\title{
OZONE DETECTION BY CRACK-INDUCED OPACITY IN RUBBER
}

\author{
P. H. Мотт \\ Geo-Centers, Inc. Ft. Washington, MD 20744 \\ C. M. Roland* \\ Chemistry Division, Code 6126, Naval Research Laboratory, Washington, DC 20375-5342
}

\begin{abstract}
Initially transparent polybutadiene develops micron-sized surface cracks when stretched and exposed to ozone. The consequent reduction in the transparency of the rubber provides a facile method for quantifying the ambient ozone concentration. The rate at which opacity develops is linearly dependent on the amount of ozone, and increases with increasing strain. This method of detecting atmospheric ozone has high sensitivity (1 ppb), a broad dynamic range, and is unaffected by the presence of other chemicals. The surface morphology of exposed material can be interpreted in terms of crack nucleation and growth.
\end{abstract}

\section{INTRODUCTION}

Ozone-induced stress cracking is normally considered a problem, diminishing the appearance and serviceability of rubber products. This cracking is the result of the rapid reaction of ozone with olefinic double bonds to form an ozonide ring. ${ }^{1}$

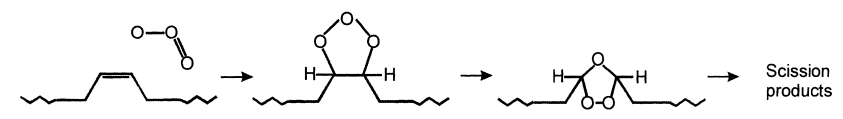

SCHEME 1.

Scission of the ring produces surface cracks when the elastomer is stretched. Previous studies of this phenomenon established the existence of three regimes ${ }^{2}$ : (I) At sufficiently low stresses, no surface cracking occurs. (II) At intermediate stresses, a small number of cracks grow to substantial size, with concomitant reduction in the failure properties. (III) High stresses yield a plethora of cracks, but the mechanical properties are minimally affected.

This behavior can be explained using fracture mechanics. ${ }^{3,4}$ The tensile stress, $\sigma_{c}$, necessary to form an ozone crack is given by

$$
\sigma_{c}=\left(\frac{G_{c} E}{\pi a}\right)^{1 / 2}
$$

where $E$ is Young's modulus, $a$ is the crack depth, and $G_{c}$ is the fracture energy (ca. $0.1 \mathrm{~J} / \mathrm{m}^{2}$ ). For $E=1 \mathrm{MPa}$ and an initial value $a=20 \mu \mathrm{m}$ (corresponding to the typical inherent flaw size in rubber $^{5}$ ), Equation (1) yields a critical tensile stress of $50 \mathrm{kPa}$ at a strain of $5 \%$. At stresses below this value (regime I), the intrinsic flaws are too small to produce ozone cracking. At stresses larger than $\sigma_{c}$ (regime II), only the largest flaws are sufficient to effect crack growth, resulting in large, isolated cracks. These cracks propagate until the critical tearing energy is exceeded and the sample fails. ${ }^{6}$ In regime III, the stress in the bulk of the material is large enough to initiate cracks, resulting in cracks uniformly covering the surface. This abundance of cracks produces a

*Corresponding author. Tel: 202-767-1719; fax: 202-767-0594; e-mail: mike.roland@nrl.navy.mil 
translucent ("frosted") appearance. At the crack tips, however, the stress amplification is low, due to the presence of closely-spaced neighboring cracks ("stress alleviation"). Cracks continue to grow, but the critical tearing energy is never exceeded because of the minimal stress concentration. Since the damaged layer at the surface is only a small fraction of the total volume, the failure properties of the elastomer remain the same, notwithstanding the frosted appearance. ${ }^{7}$

From observations on isolated cuts in rubber specimens, the crack growth rate has been shown to be independent of stress, depending only on ozone concentration for a given material. ${ }^{8}$ At temperatures sufficiently above the glass transition temperature, the availability of ozone becomes the rate-limiting factor for crack growth. ${ }^{9,10}$

The objective of most studies of ozone cracking is to improve a rubber's resistance to it. Hence, such experiments usually employ very high ozone concentrations, e.g., $10^{5} \mathrm{ppb}$, far above normal ambient levels of 10-100 ppb. ${ }^{11,12}$ There have been some attempts to use the cracking behavior of rubber as a measure of ozone concentration. For example, a differential creep technique was developed, based on the reduction of cross-sectional area accompanying ozone deterioration of rubber. ${ }^{13-15}$ Another approach is to measure the length of cracks, and deduce the ozone concentration by comparison to calibration curves. ${ }^{11,16,17}$ These methods are fraught with problems; for example, the distribution of crack lengths is a complex function of time and strain, and depends non-linearly on ozone concentration. ${ }^{11}$

There are many other ways to measure the concentration of ambient ozone. ${ }^{18,19}$ Accurate commercial instruments are expensive and ill-suited for field use, while portable methods suffer from poor accuracy, or are susceptible to interference from other chemicals. The need for accurate, portable ozone detection methods has grown of late, a result of regulatory compliance issues and health concerns. Ambient ozone levels as high as $244 \mathrm{ppb}$ have been measured recently in the United States. ${ }^{20}$ This is more than twice the Environmental Protection Agency's "Air Quality Standard" (120 ppb, averaged over a one hour period, and $80 \mathrm{ppb}$ averaging over an eight-hour period $\left.{ }^{21}\right)$. In 1997, 38 metropolitan areas, having a population of 100 million, did not meet this standard. ${ }^{22}$ The US Occupational Safety and Health Administration has established a workplace ozone "permissible exposure limit" of $100 \mathrm{ppb}$, averaged over eight hours. ${ }^{23}$

In this paper we demonstrate that ambient ozone levels can be quantified by measuring the opacity that accompanies ozone-cracking of rubber films. ${ }^{24,25}$ Cracks in the rubber film cause deviation of the incident light from its original direction. Measurement of this reduction in intensity can be quantitatively related to the ozone concentration, providing a low-cost, portable detection method that has high sensitivity, a broad dynamic range, and is free of interferences from other pollutants.

\section{EXPERIMENTAL}

Results reported herein were obtained using a blend of two commercial 1,4-polybutadienes, $83 \%$ by weight Diene 55AC10 (Firestone Synthetic Rubber \& Latex Company) and 17\% Taktene ${ }^{\circledR} 1203$ (Bayer Corporation). The curative, dicumyl peroxide, was dissolved in hexane, and aliquots added to the raw polymer to yield 0.03 to $0.06 \mathrm{phr}$. Following evaporation of the solvent, the rubber was mixed on a two-roll mill, followed by compression molding $\left(40\right.$ minutes at $\left.150^{\circ} \mathrm{C}\right)$ to yield cured films $(65-\times 13-\times 1.6-\mathrm{mm})$.

A steady flow $(6 \mathrm{~L} / \mathrm{m})$ of ozone-laden air (Environics Series 300 ozone generator) was passed into a Plexiglas ${ }^{\circledR}$ chamber. A return stream was monitored to determine the ozone concentration. The sample was fitted in a frame, which could be placed in the chamber with minimal disturbance. The sample was then elongated with an external pull rod, and the imposed strain maintained constant during the experiment. Nitrogen oxide, nitrous oxide, sulfur dioxide, methane, and carbon monoxide, contaminant gases used to test for interference with the ozone-cracking response of the rubber, were obtained from Air Products, Inc. 
A HeNe laser beam (Uniphase 1104P) was expanded to illuminate a $10 \mathrm{~mm}$ diameter area of the rubber film, and the transmitted light focused onto a photodiode detector (EG\&G Inc. UV100). The transmitted intensity was normalized by the value measured immediately after stretching the rubber; this ratio is referred to as the relative transmission.

\section{RESULTS}

Figure 1(a) illustrates the three regimes of ozone-cracking behavior. These samples were exposed to $10 \mathrm{ppb}$ ozone for approximately one day, either unstrained (regime I), elongated 18\% (regime II), or $121 \%$ (regime III). The unstrained sample is indistinguishable from unexposed rubber, while the regime II sample has large, distinct cracks. The regime III sample has become completely opaque, due to cracks uniformly covering its surface. These are 5-10 $\mu \mathrm{m}$ in depth, and spaced about 20 $\mu \mathrm{m}$ apart.

The difference between the crack morphology for regimes II and III is illustrated more clearly in Figure 1(b). Two samples having slightly different moduli were held at $40 \%$ elongation (corresponding to respective stresses of 0.28 and $0.36 \mathrm{MPa}$ ) for 30 minutes, while exposed to $100 \mathrm{ppb}$ ozone. For the rubber at the higher stress, no surface cracks are apparent without magnification (regime III). Increasing the strain beyond $40 \%$ does not change the appearance of the translucent surface. In the softer rubber, however, individual cracks are easily discernable. Reducing the stress in this sample by lowering the strain results in fewer, but larger, cracks. This is regime II behavior.

The relative transmission for rubber (in regime III) exposed to different ozone concentrations is displayed in Figure 2. The error bars represent the standard deviation of the data. When the relative
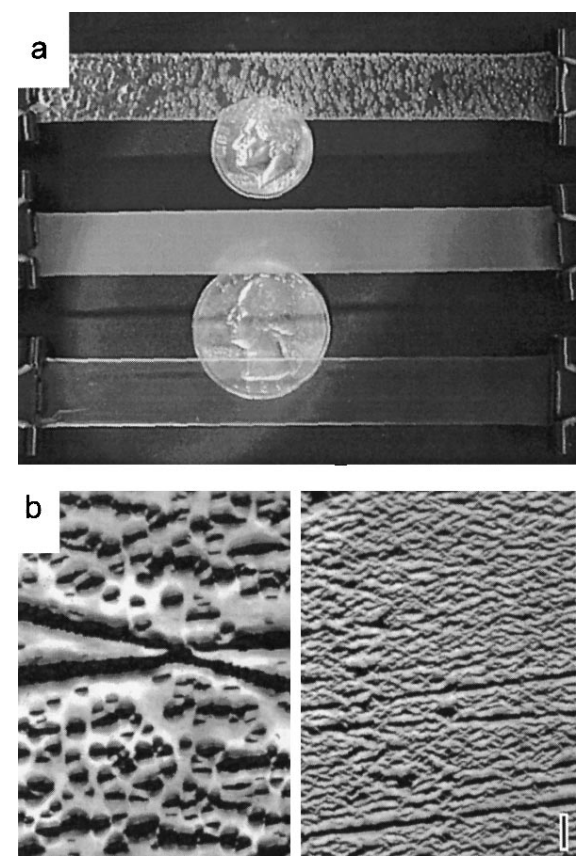

FIG. 1. - (a) Photographs of rubber strips exposed to $10 \mathrm{ppb} \mathrm{O}_{3}$ for 24 hours, demonstrating the three regimes of ozone cracking. Top: regime II, sample elongated $18 \%$ during exposure; middle: regime III, $121 \%$ elongation; bottom: regime I, sample unstrained. (b) Optical micrographs comparing the crack morphology of two rubbers with different modulus, elongated $40 \%$ for 30 minutes in $100 \mathrm{ppb} \mathrm{O}_{3}$. The stress on the rubber was $0.28 \mathrm{MPa}$ (left) and $0.36 \mathrm{MPa}$ (right). The vertical scale bar in the lower right hand corner indicates $100 \mu \mathrm{m}$. 


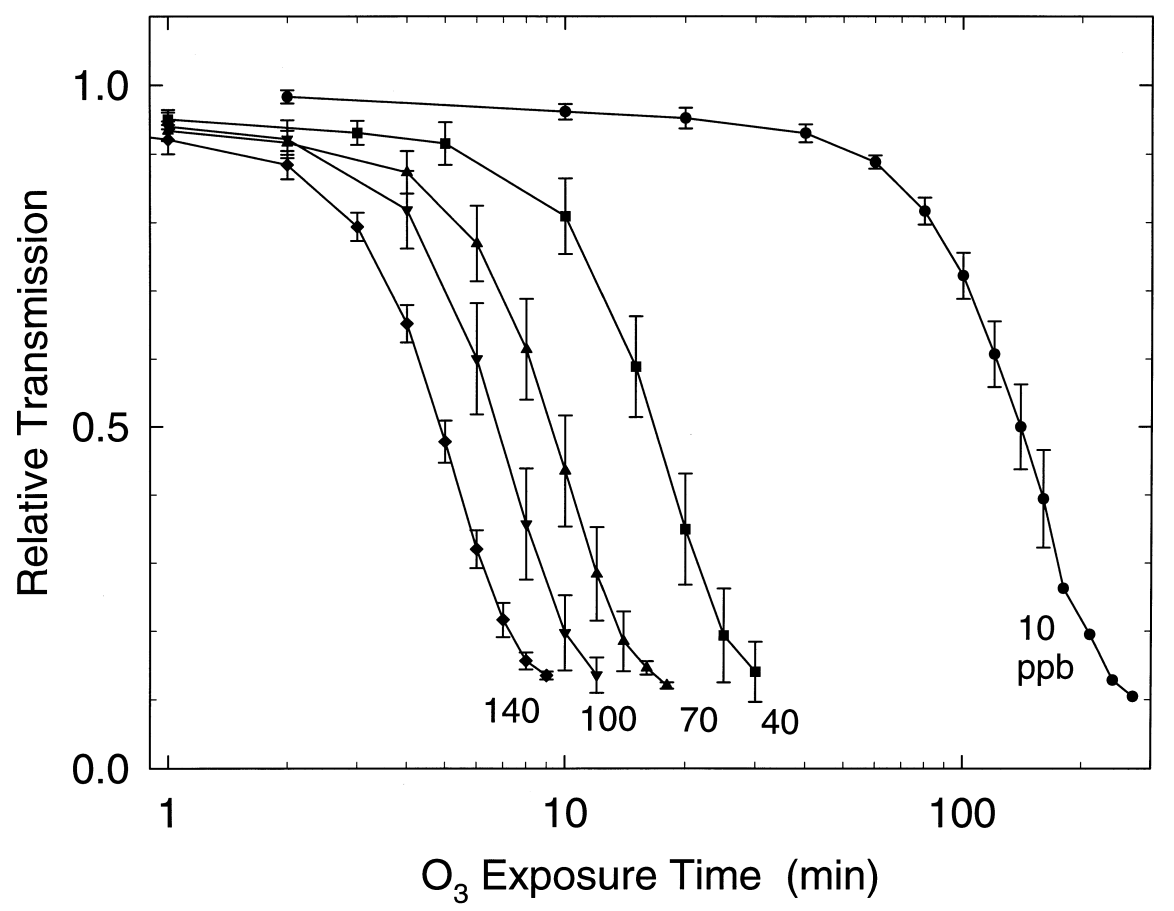

FIG. 2. - Relative transmission for rubber extended $121 \%$ while exposed to the indicated ozone concentration. The error bars represent one standard deviation of the four or five trials.

transmission reaches about $10 \%$, the appearance of the rubber is similar to the nearly opaque sample in Figure 1(a).

Increasing the ozone concentration decreases the time to achieve opacity. Moreover, the parallelism of the curves in Figure 2 suggests that varying the ozone level changes only the time scale of the process. The data can be horizontally shifted to yield a "master curve," as shown in Figure 3 for a $100 \mathrm{ppb}$ reference concentration of ozone. The shift factors used to obtain this superposition are displayed as an inset to the figure. The shifting is linearly dependent on ozone concentration. Such a relationship simplifies obtaining a universal calibration between rubber opacity and ozone concentration.

Figure 4 illustrates that changing the strain is comparable to the effect of changing the ozone concentration. For example, while a decrease of elongation from 121 to $76 \%$ retards the development of opacity, there is no effect on the shape of the response curve. This indicates that the sensitivity of the rubber to ozone may be adjusted by changing its strain, without changing the nature of the calibration.

Experiments were carried out to determine if exposure to various gases would change the response to ozone. Samples of rubber were exposed to five gases (diluted with nitrogen, except for $\mathrm{NO}_{2}$, which was diluted with air) at $10 \mathrm{ppm}$ concentration for one hour. Subsequently these rubber strips were stretched to $74 \%$ elongation and exposed to $200 \mathrm{ppb}$ ozone. The light transmission was measured during the exposure, to determine the time required for the optical clarity to be reduced in half. These results are displayed in Figure 5. Clearly any effect of gas exposure is less than the scatter in the data.

The absence of any evidence that gas exposure influences the ozone response of the rubber is unsurprising. Compared to ozone, the reaction rate of these gases with polybutadiene is negligible at room temperature. 


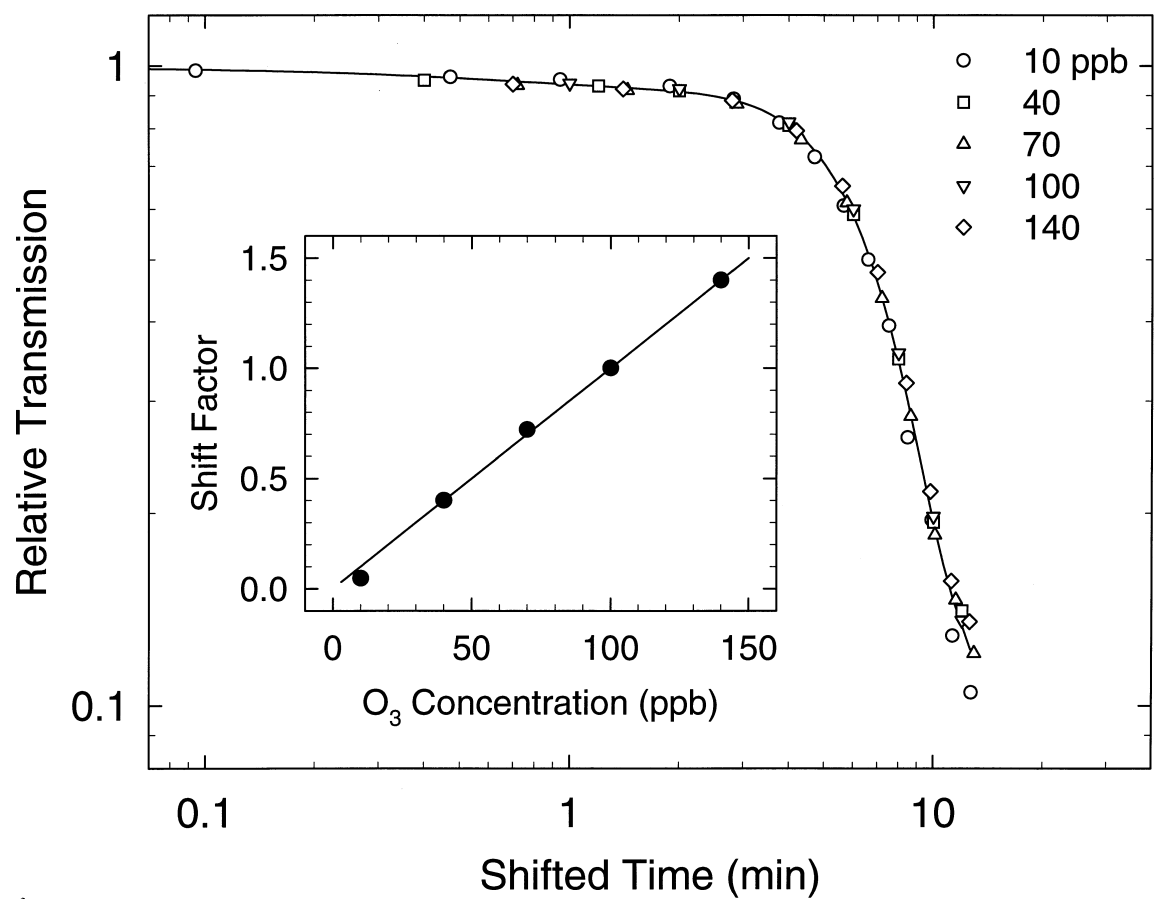

FIG. 3. - Ozone cracking "master curve" (100 ppb reference concentration), obtained by superposition of the data in Figure 2 . The inset shows the factors by which the abscissa values were shifted to generate the master curve.

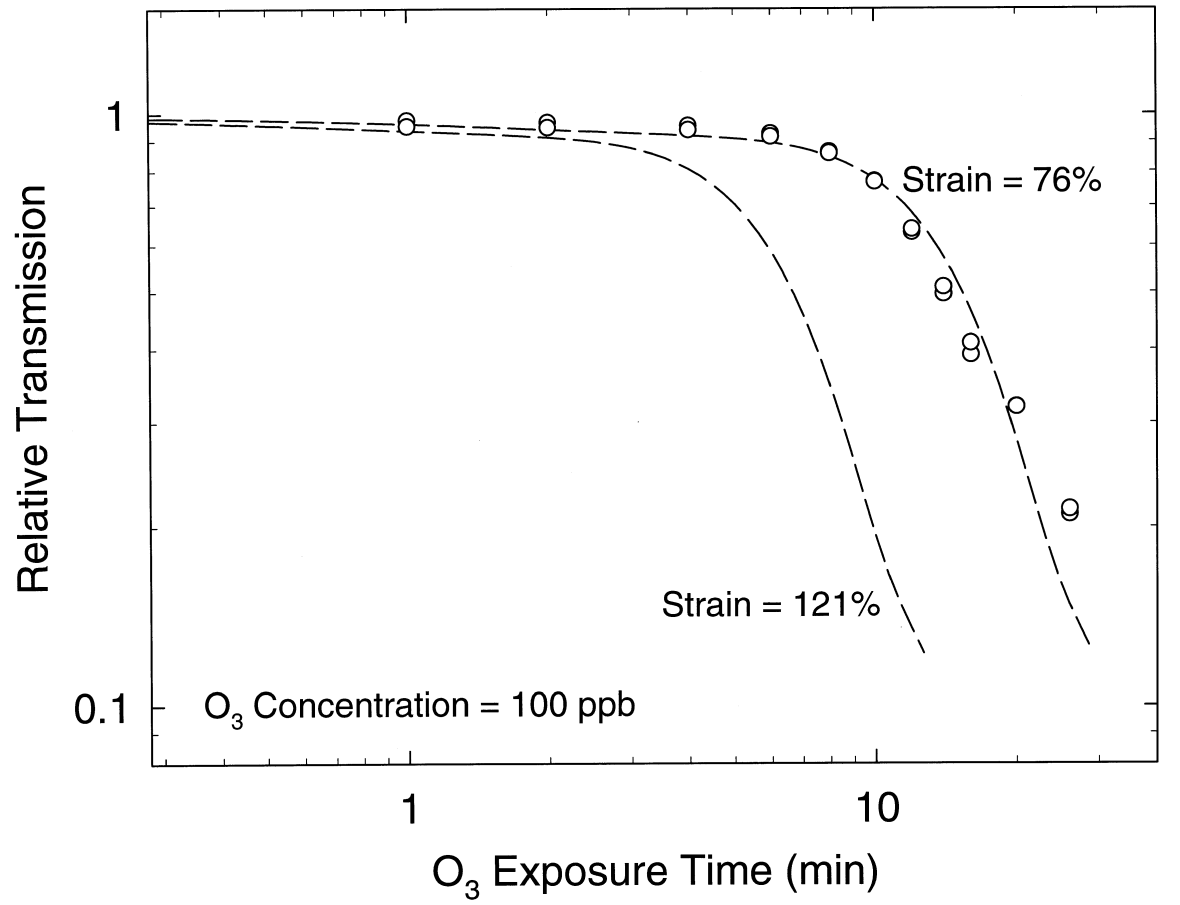

FIG. 4. - Relative transmission of rubber for two different elongations. The open circles represent measurements on samples elongated $76 \%$, while the broken lines are the master curve from Figure 3, including after a time-scale shift by a factor of 2.3 . 


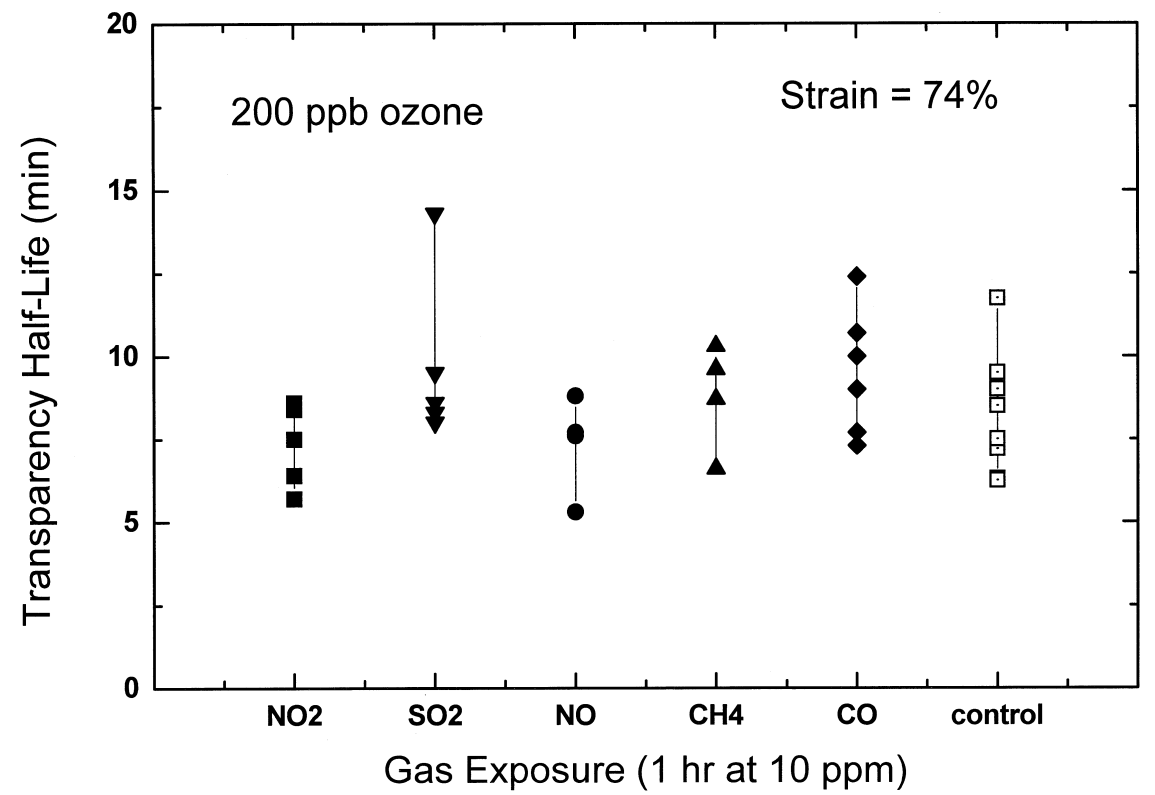

FIG. 5. - The time for loss of half the initial transparency of films exposed to $10 \mathrm{ppm}$ of the indicated gasses for $1 \mathrm{~h}$, prior to $200 \mathrm{ppb}$ ozone at $74 \%$ elongation. Any interference from these gases with the ozone-cracking process is less than the scatter in the data.

\section{DISCUSSION}

\section{CRACK MORPHOLOGY}

The crack spacing due to ozone attack is determined by the density of nucleation sites and the stress at the crack tip. For parallel cracks, the stress at the tip is lower than for a single, isolated crack of the same dimensions. The stress concentration factor, defined as the ratio of the stress at the crack tip, $\sigma_{t}$, to the applied stress, $\sigma$, is 26

$$
\frac{\sigma_{t}}{\sigma}=\frac{k_{1}}{(2 r)^{1 / 2}}
$$

where $r$ is the crack tip radius, and $k_{1}$ the stress intensity factor for evenly spaced parallel edge cracks in a half plane. The latter is defined as

$$
k_{1}=\mathrm{F}(b / s)\left(\frac{b a}{s}\right)^{1 / 2}
$$

where $2 b$ is the crack spacing, and $s$ is the sum of $a$ and $b .{ }^{27} \mathrm{~F}(b / s)$ represents the polynomial

$$
\begin{aligned}
\mathrm{F}(b / s)=\pi^{1 / 2}[ & +\frac{1}{2}\left(\frac{b}{s}\right)+\frac{3}{8}\left(\frac{b}{s}\right)^{2}+\frac{5}{16}\left(\frac{b}{s}\right)^{3}+\frac{35}{128}\left(\frac{b}{s}\right)^{4} \\
& +\frac{63}{256}\left(\frac{b}{s}\right)^{5}+\frac{231}{1024}\left(\frac{b}{s}\right)^{6}+22.501\left(\frac{b}{s}\right)^{7} \\
& \left.-63.502\left(\frac{b}{s}\right)^{8}+58.045\left(\frac{b}{s}\right)^{9}-17.577\left(\frac{b}{s}\right)^{10}\right]
\end{aligned}
$$


In Figure 6 this stress concentration factor is plotted, assuming $r=1 \mu \mathrm{m}$, as a function of crack depth for different crack spacings.

The initial crack spacing is determined by the number of nucleation sites, which in turn is governed by the applied stress and the intrinsic flaw size distribution. As the initial cracks grow, the degree of stress concentration reaches a limiting value. As seen in Figure 6, a maximum in stress concentration is realized when the crack depth is equal to about one-third of the spacing $\left(a \approx \frac{2}{3} b\right)$. This is consistent with St. Venant's principle, ${ }^{26,28}$ whereby the stress concentration around a flaw is expected to become negligible at a distance three times the flaw dimension. Once the crack achieves this depth, the material between the cracks (shown as the volume 2 bat in Figure 6) is unloaded, so that new cracks do not initiate. For a distribution of crack sizes, growth of deeper cracks alleviates the stress on smaller cracks, thereby preventing propagation of the latter.

Microscopic examination of ozone-cracked specimens revealed that the growth of many cracks does indeed terminate due to strain relief from neighboring cracks. Furthermore, in fully opaque (regime III) specimens, crack initiation was always observed to occur away from the original crack surfaces. When stress-raising flaws were intentionally introduced in samples, the resulting cracks achieved the same size as cracks far from any stress concentration. These observations are consistent with crack growth that is independent of stress.

Consequently, the sensitivity of opacity development to strain (Figure 4), which at first sight contradicts the conclusions of previous studies ${ }^{8}$ that ozone crack growth rates are independent of stress, is in fact due to the stress-dependence of crack initiation. During the initial stages of ozone cracking, prior to any interference among neighboring cracks, the distribution of crack initiation sites is preserved and amplified. This means that the morphology of the ozone cracking provides

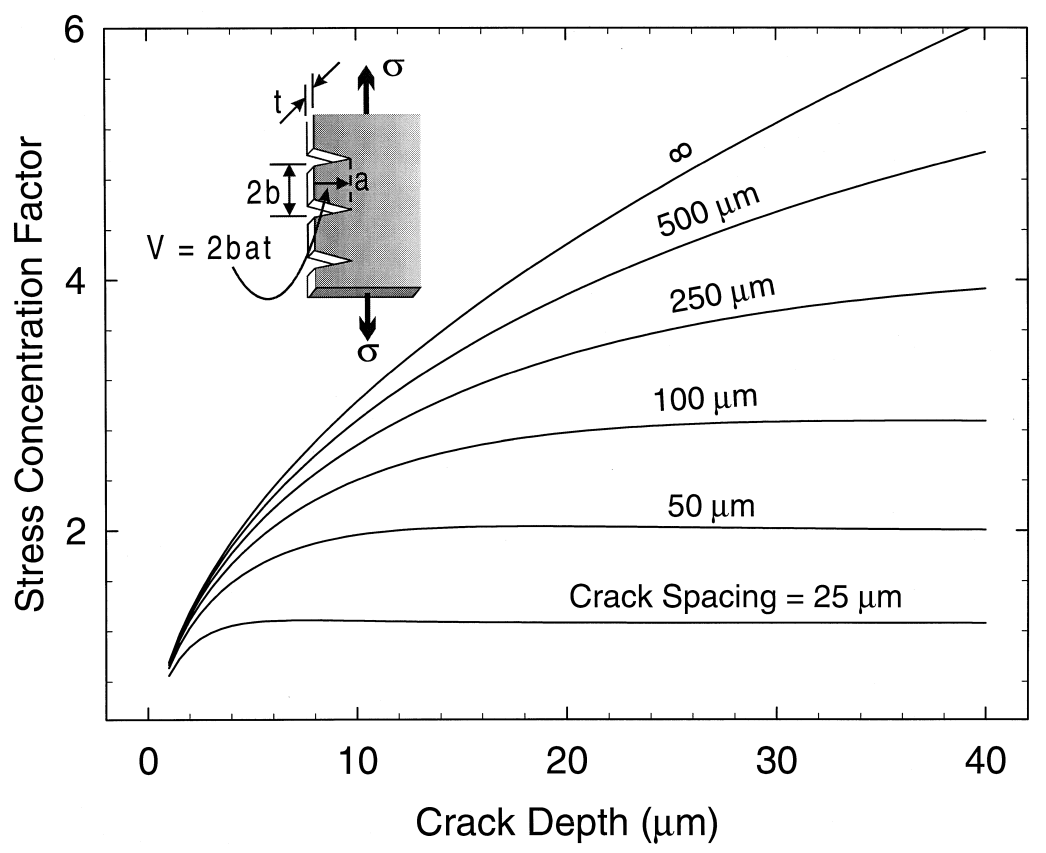

FIG. 6. - The quantity $\sigma / \sigma_{t}$, calculated using Equations (2) through (4), as a function of crack depth, for the indicated crack spacings. Radius of crack tip was $1 \mu \mathrm{m}$. For isolated cracks, the stress is continuously amplified as the crack grows deeper. For closely spaced cracks, the stress concentration reaches a limiting value, the result of alleviation from neighboring cracks. 
direct information concerning the distribution of crack nuclei. We intend to pursue more detailed analysis of ozone crack initiation and growth, in order to obtain insights into the intrinsic flaws in rubber, a topic of current interest. ${ }^{29-31}$

\section{OZONE DETECTION}

The loss of optical clarity due to ozone-induced cracking is an obvious means for detecting ozone. The independence of the shape of the response function (Figures 2 and 3), along with the linearity of the shift factors used to obtain a master curve, facilitate quantitative measurement. The ability to change the sensitivity by changing strain allows for a wide range of concentrations and measurement times. Of course, these ranges can be further extended by altering the formulation of the rubber.

To illustrate one possible approach for ozone detection, Figure 7 shows the time required for a $50 \%$ reduction in the initial transmitted intensity as a function of ozone concentration. The smooth curve is the prediction based on fits to the experimental data in Figures 2 and 3; the points are separate measurements. The agreement is excellent, excepting the datum at $10 \mathrm{ppb}$. At this low level, our results are less reliable due to systematic error in controlling the output of the ozone generator.

Another approach to determine the ozone concentration is to expose the rubber for a given length of time, and then measure the opacity, with the concentration determined using a calibration curve. Figure 8(a) displays three such calibration curves, for different measurement times. The smooth curve is again the prediction based on fits to the previous data, and the points are measurements. The agreement is quite satisfactory. The maximum detectable ozone level is limited by attainment of an essentially opaque rubber film. The optimum response time depends on the amount of ozone present and the desired accuracy. Figure 8 (b) shows the uncertainty, $\delta\left[\mathrm{O}_{3}\right]$, of a single determination,

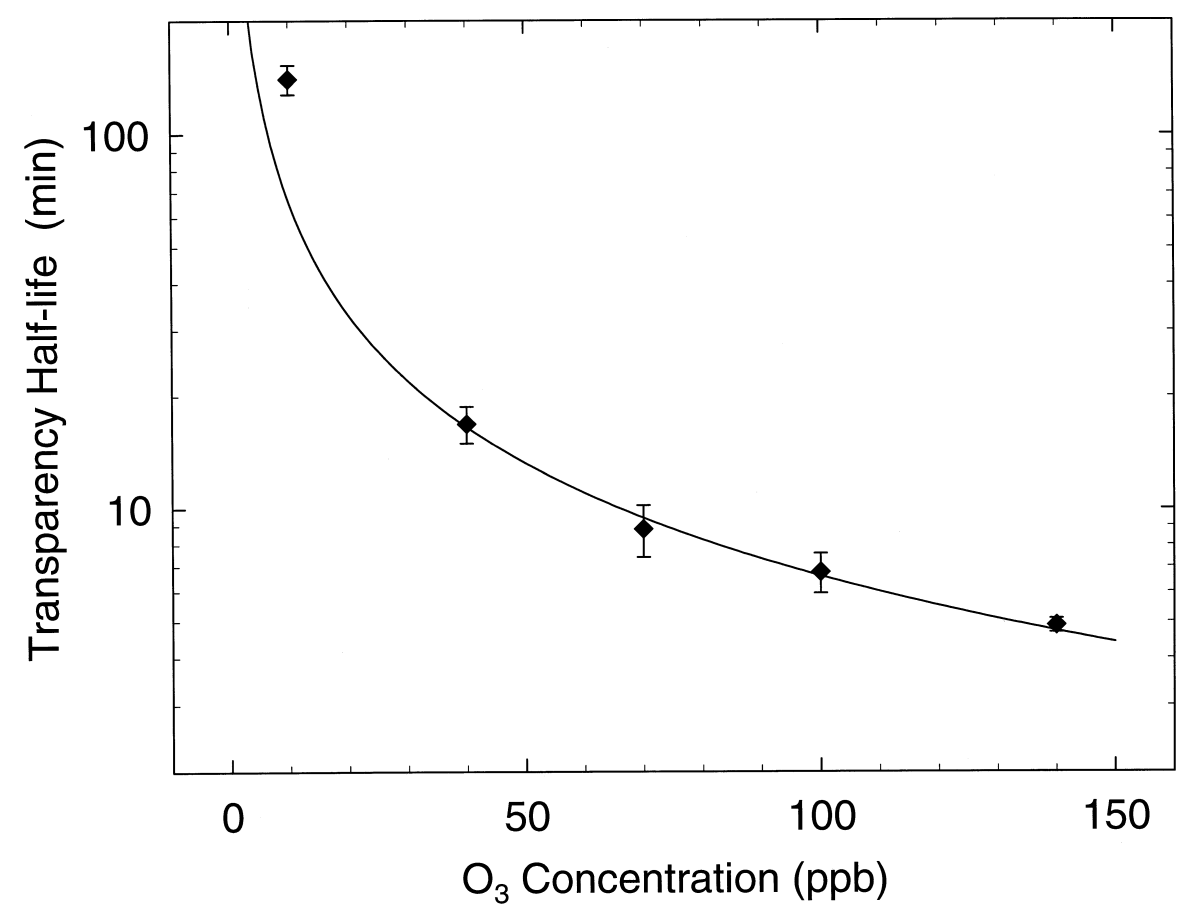

FIG. 7. - The dependence on ozone concentration of the time required for loss of half the initial transparency. The smooth curve is derived from Figure 3; the points are measured data. The error bars represent one standard deviation. 


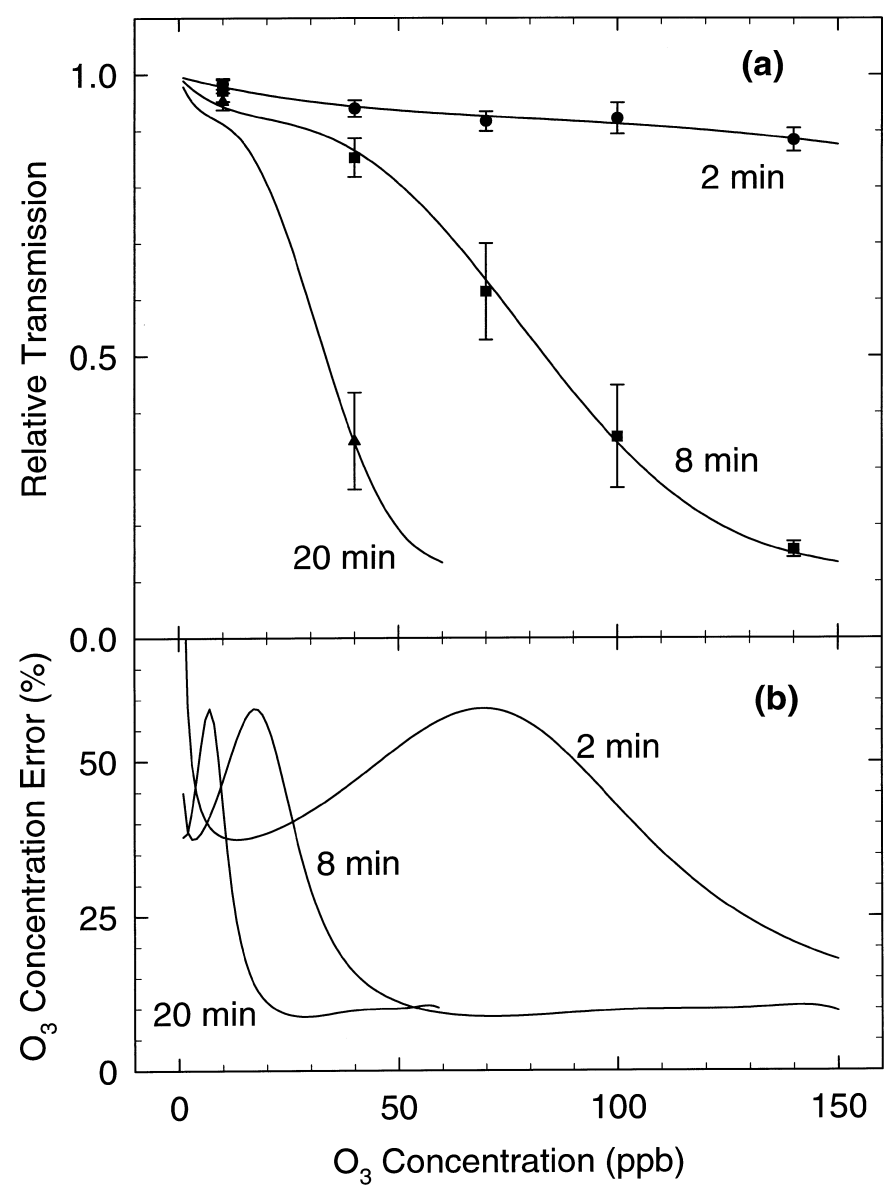

FIG. 8. - (a) Relative transmission of samples exposed two, eight, and twenty minutes to various concentrations of ozone. The error bars represent one standard deviation. (b) The uncertainty in the determination of ozone concentration, as calculated from Equation (5), for the calibration curves above.

calculated by propagation of error,

$$
\delta\left[\mathrm{O}_{3}\right]=\frac{\delta I}{\left(\frac{\partial I}{\partial\left[\mathrm{O}_{3}\right]}\right)}
$$

where $\delta I$ is the scatter in the relative transmission measurement (shown by error bars in Figure $8[\mathrm{a}])$, and $\partial I / \partial\left[\mathrm{O}_{3}\right]$ is the slope of the calibration. For this particular measurement, eight minute exposure can be seen to yield the broadest range of detectable concentrations, with an uncertainty less than $10 \%$ over most of that range. Obviously, additional measurements could be made to reduce the uncertainty.

\section{SUMMARY}

By measuring the light transmission through stretched rubber, ambient ozone can be routinely determined down to $1 \mathrm{ppb}$ levels. The sensitivity and dynamic range of the technique can be adjusted by changing the applied strain or by changing the modulus of the rubber. This variability of the sensitivity is due to the dependence of crack initiation on the applied stress. The crack growth rate per se is independent of the strain. 


\section{ACKNOWLEDGMENTS}

We are grateful to Environics Inc. for the use of their ozone apparatus and A. S. Argon for helpful discussions. This work was supported by the Office of Naval Research.

\section{REFERENCES}

${ }^{1}$ L. G. Wade, “Organic Chemistry,” 4th ed., Prentice Hall, Upper Saddle River, NJ, 1999.

${ }^{2}$ R. G. Newton, J. Rubber Res. 14, 27 (1945); ibid 14, 41 (1945).

${ }^{3}$ M. Braden and A. N. Gent, Kautsch. Gummi 14, WT157 (1961).

${ }^{4}$ E. H. Andrews, D. Barnard, M. Braden, and A. N. Gent, "The Chemistry of Rubberlike Substances," L. Bateman, Ed., Wiley, New York, 1963, ch. 12.

${ }^{5}$ I. S. Choi and C. M. Roland, Rubber Chem. Technol. 69, 591, (1996).

${ }^{6}$ G. J. Lake and P. B. Lindley, J. Appl. Polym. Sci. 9, 2031 (1965).

${ }^{7}$ C. M. Roland and J. W. Sobiesky, Rubber Chem. Technol. 62, 683 (1989).

${ }^{8}$ M. Braden and A. N. Gent, J. Appl. Polym. Sci. 3, 90 (1960).

${ }^{9}$ A. N. Gent and J. E. McGrath, J. Polym. Sci., Part A 3, 1473 (1965).

${ }^{10}$ A. N. Gent, "Science and Technology of Rubber," 2nd ed., James E. Mark, et al. Eds., Academic Press, San Diego, 1994, ch. 10 .

${ }^{11}$ E. Serrano, M. Castro, and A. Macias, Atmos. Environ. Part A 27, 431 (1993).

${ }^{12}$ G. J. Lake and P. G. Mente, Polym. Degradation Stab. 49, 193 (1995).

${ }^{13}$ F. L. Roth and R. D. Stiehler, India Rubber World 118, 367 (1948).

${ }^{14}$ R. F. Shaw and S. R. Adams, Anal. Chem. 23, 1649 (1951).

${ }^{15}$ A. G. Veith, ASTM Spec. Tech. Publi. no. 229, 97 (1958).

${ }^{16}$ J. S. Rugg, Anal. Chem. 24, 818 (1952).

${ }^{17}$ A. G. Veith, Rubber Chem. Technol. 45, 293 (1972).

${ }^{18}$ G. Gordon, W. J. Cooper, R. Rice, and G. Pacey, Eds., "Disinfectant Residual Measurement Methods,” 2nd ed., American Water Works Association Research Foundation, Denver CO, 1992.

19“'Air Quality Criteria for Ozone and Related Photochemical Oxidants,” U.S. EPA Report No. EPA/600/P-93/004aF, July 1996.

20 “Aerometric Information Retrieval System,” US Environmental Protection Agency, Office of Air Quality Planning and Standards, Information Transfer and Program Integration Division (ITPID), Research Triangle Park, North Carolina.

${ }^{21}$ Fed. Regis., 40 CFR part 50, 18 July 1997.

${ }^{22}$ Fed. Regis., 63 FR 2804, 5 June 1998.

${ }^{23}$ Code of Federal Regulation, 29 CFR 1910.1000, table Z-1.

${ }^{24}$ P. H. Mott and C. M. Roland (to U.S. Dept. of the Navy), U.S. Patent Appl. 625506 (Feb. 10, 1998), licensed by Environics Inc., Tolland, CT.

${ }^{25}$ P. H. Mott and C. M. Roland, NASA Tech Briefs, September 1997, p. 12a.

${ }^{26}$ F. A. McClintock and A. S. Argon, Eds., "Mechanical Behavior of Materials," Addison-Wesley, Reading, MA, 1966, ch. 11.

${ }^{27}$ G. C. Sih, "Handbook of Stress-Intensity Factors; Stress-Intensity Factor Solutions and Formulas for Reference," Institute of Fracture and Solid Mechanics, Lehigh University, Bethlehem, PA, 1973.

${ }^{28}$ G. Horvay, J. Mech. Phys. Solids 5, 77 (1957).

${ }^{29}$ C. M. Roland, I. S. Choi, and M. J. Schroeder, Rubber Plast. News, 27(11), 14 (January 12, 1998).

${ }^{30}$ I. S. Choi and C. M. Roland, Rubber Chem. Technol. 70, 202 (1997).

${ }^{31}$ C. M. Roland and C. R. Smith, Rubber Chem. Technol. 58, 806 (1985). 